\title{
Experimental Studies on Deformation in Nacre from Red Abalone
}

\author{
K. S. Katti*, D. R. Katti*, A. P. Bhosle* \\ *Department of Civil Engineering, North Dakota State University, Fargo, ND 58105
}

Nacre, the inner lustrous layer of many molluscan shells is a material of great interest due to its exceptional mechanical properties [1]. Nature has optimized the structure of this material to a level that is unique and uncommon in engineered materials. Much work has been done on characterizing its structure, properties and growth [2]. In our previous work we have used threedimensional finite element modeling techniques to model details of nano-meso and macro structure of nacre and evaluate its role on mechanical response [3-6]. Some of the results from these studies are as follows: organic has a high elastic modulus and yield strength [3,4], mineral contacts through aragonite have negligible role on stress-strain response of nacre [5], nanoscale asperities at organic-inorganic interfaces have a very small role mechanical response of nacre [6].

In this work we present experimental studies on samples of nacre. These studies involve tensile testing on dogbone shaped samples of nacre and also three point bend tests. Dogbone shaped nacre samples were carved out of samples of red abalone (Haliotis rufescens) and held in specially designed grips (Fig. 1a,b,c and d). These samples were gripped in the device using carbide pins run through holes drilled in the nacre samples. These samples were loaded to failure in tension. Scanning electron micrographs were taken using a JEOL 6000 JSM $6300 \mathrm{~V}$ electron microscope from surface of failed samples. Platelet pullout (Fig. 2a ) and large deformations in the organic phase (Fig. 2b) are observed. These samples were also subjected to three-point bend tests as shown in Fig. 3a. SEM micrographs were obtained across the crossection of the samples from the compression to tension faces. Distinctly different microstructures are observed for the compression and tension faces as shown in Fig. 3a. Micrograph at the geometric neutral axis is shown in Fig. 3b. Fig 3c shows the micrograph interface where the transition appears to occur from compression to tension. Using this value as the distance of neutral axis, we calculate the modulus of the sample to be $48.48 \mathrm{GPa}$. Further close examination of the fractured surface indicate the presence of new features: interlocks between nacre platelets (Fig. 4a). We have also incorporated these interlocks in our FE models (Fig 4a-inset) [7] that show that these interlocks play a significant role on stress-strain response of nacre role of large deformations in organic phase (Fig 4b). Nanoindentation experiments were done nacre samples at loads varying from 10 $\mu \mathrm{N}$ to $10,000 \mu \mathrm{N}$. Nanoindentation at low loads bring about the influence of nanostructure which is often overlooked by high load nanoindentation experiments as shown in Fig. 4c.

\section{References}

[1] J.D.Currey, Proc. R. Soc. London, Series B, 196 (1977) 443.

[2] A. Lin, M. A. Meyers, Mater. Sci. Engr. A, 390 (2004) 27.

[3] D.R. Katti, and K.S. Katti, J. Mater. Sci., 36(6) (2001) 1411.

[4] D.R. Katti, K.S. Katti, J. Sopp, and M. Sarikaya, J. Theo. Comp. Poly. Sci. (2001)11 (5) 397.

[5] K.S. Katti, D.R. Katti, J. Tang and M. Sarikaya, in press J. Mater. Sci.(2005).

[6] D. R. Katti, S. Pradhan, and K. S. Katti, Rev. Adv. Mater. Sci. 6 (2004) 162.

[7] K. S. Katti, D. R. Katti, S. Pradhan, A. P. Bhosle, under review J. Mater. Res. (2005).

[8] This work is supported by a grant from National Science Foundation (project \# 0115928). The program manager is Dr. K. Chong. 


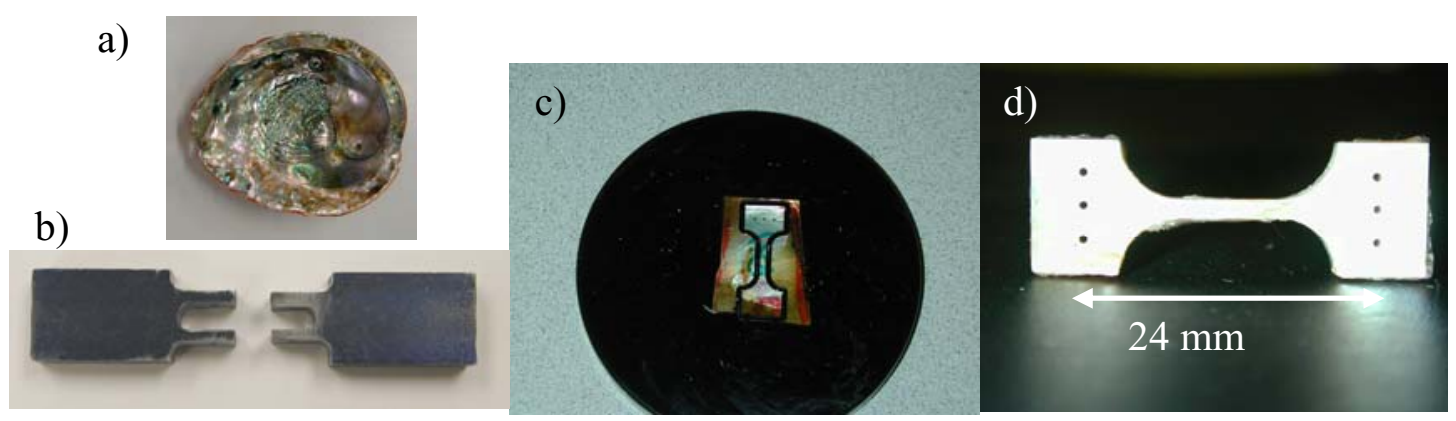

Fig. 1. a) A red abalone shell. b) fixture designed for tensile testing c) dogbone shaped sample of nacre d) dogbone shaped sample of nacre showing holes for gripping with tensile fixture.
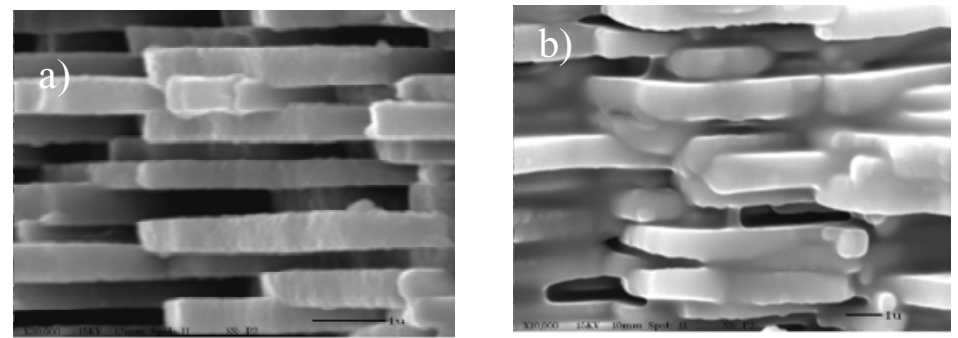

Fig. 2 a) SEM micrographs of sample loaded to failure in tensile testing showing a) platelet pullout and b) large deformations in organic phase.

a)
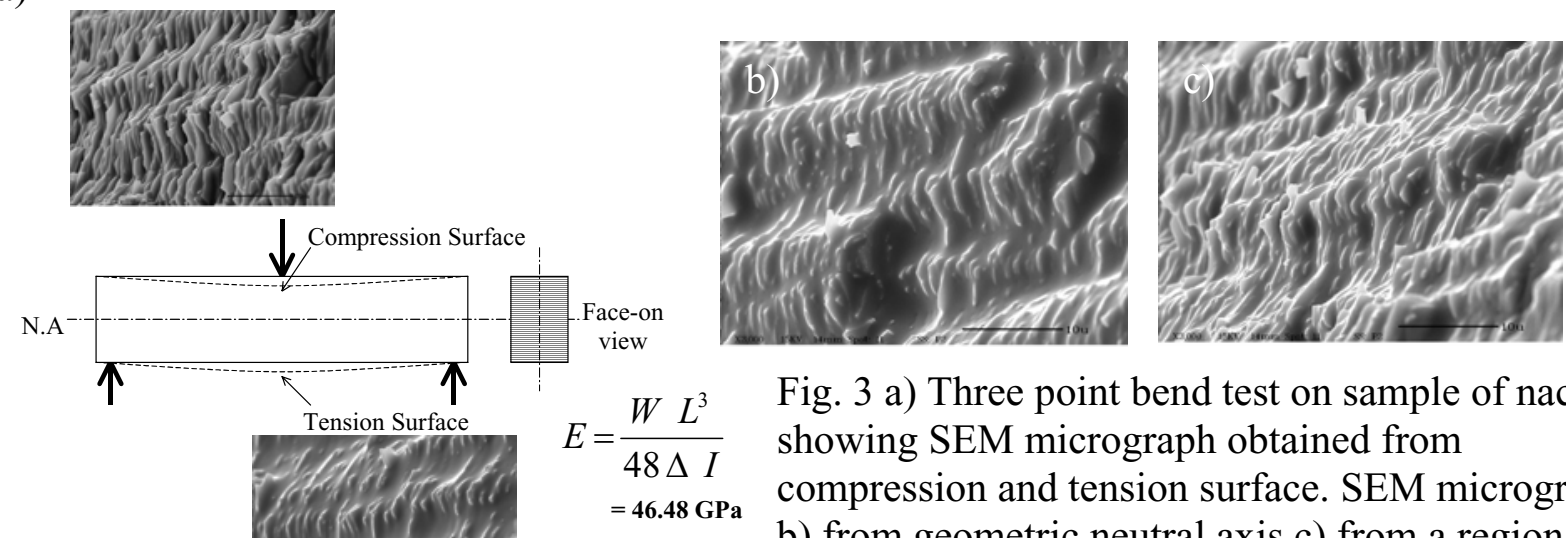

Fig. 3 a) Three point bend test on sample of nacre showing SEM micrograph obtained from compression and tension surface. SEM micrograph b) from geometric neutral axis.c) from a region showing $\mathrm{C}-\mathrm{T}$ transmission in microstructure

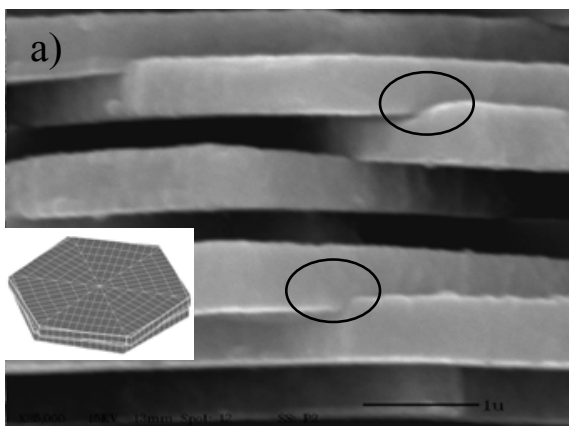

b)

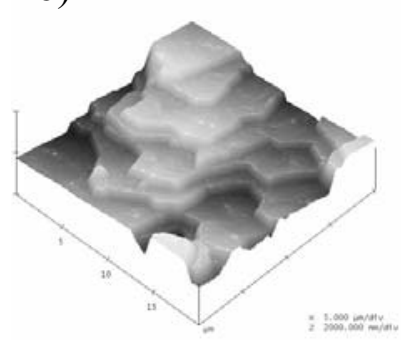

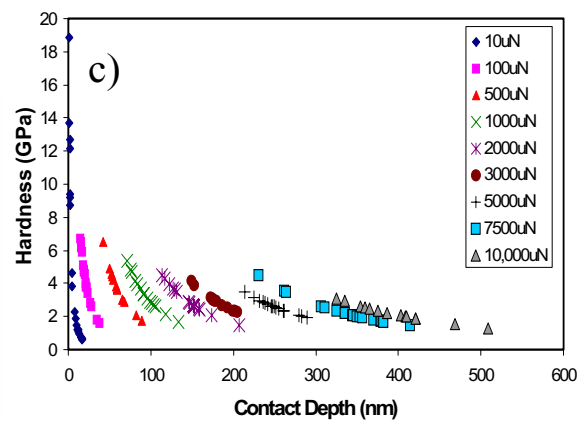

Fig. 4 a) SEM micrograph showing interlocks in aragonite platelets with inset showing 3D FEM of interlocks b) AFM image of surface of nacre c) measure of hardness of nacre for varying loads. 